\title{
The effect Culture Dimensions on Quality of Integrated Reporting from the perspective of stakeholders
}

\author{
Ali Khalaf Gatea Al-Jubouri', Haider Ali Jarad Al Masoudi ${ }^{2}$ \\ 1. Technical Institute in Nasiriya - Southern Technical Universityali.khalaf83@stu.edu.iq \\ 2. College of Administration and Economics, haider.almasudy@uokerbalaa.edu.Iq
}

\begin{abstract}
The preparation of integrated Reporting is a new form of reports that aims to provide a comprehensive picture of the performance of the economic unit, and because the quality of reporting is a critical aspect of integrated reports, so the research aims to demonstrate the impact of cultural dimensions on the quality of integrated reports from the point of view of stakeholders, assuming that the dimensions Cultural has a significant relationship with the extent to which the quality of integrated reporting is achieved, that the most important findings of the research states that cultural dimensions have a role in enhancing the quality of integrated reporting, that cultural dimensions have very important effects on ethics, social responsibility of economic units, organizational culture and administrative practices, The research recommends, in light of the different cultural dimensions between different business environments, whether national or international, the need to interact with the environment and the societies in which the economic unit operates, to enable it to provide environmental, social or ethical information, along with financial, strategic and governance information in an annual report.
\end{abstract}

Keywords: Culture Dimensions, Quality, Integrated Reporting .

\section{Introduction}

The dramatic development of economic conditions highlights actual and potential shortcomings in the historical information of economic units. Because it cannot meet the diverse needs of investors for information consistent with the needs of economic development. Inability to provide stakeholders with adequate visibility. With regard to critical success factors, opportunities, risks and management plans as a more integrated perspective, this changing business environment and increasing complexity. As a result of the increasing need for non-financial information for economic units in light of the inability of their financial reports to provide information relevant to decision-making by stakeholders, which may relate to social or environmental relations as well as the cultural and cognitive diversity of the individuals working in them. He called for the emergence of a new type of integrated reporting, which is called integrated reporting (IR) to be an alternative to traditional financial reporting limited to financial activities or those that the economic unit is obliged to report. Because of its nature that could lead to the formation of a contingent liability in the future. Integrated reporting (IR) has gained significant attention in recent years as an emerging approach to integrated reporting on the activities of financial and non-financial economic units. 


\section{Theoretical side}

\subsection{The values of the Cultural Dimensions}

Since the fifties of the last century, cultural dimensions have played an important role in the humanities and social sciences, and many theories have emerged, which emphasize the need to study national culture, and its impact on society from a social and economic point of view, in light of the rapid development and its technological effects, as well as competitiveness on world leadership after The Second World War.

(Fink et al. al, 2006) Kluckhohn, 1951 perhaps the study was one of the first studies that dealt with cultural dimensions from a quantitative scientific research perspective, as it set a standard for all additional research on developing and measuring the dimensions of cultural values. It assumed five problem areas in societies and reformulated them as follows:

a. Human Nature Orientation: What is the nature of the innate human personality?

b. Man Nature Orientation: What is the relationship of man to nature and the supernatural?

c. Time Orientation: What is the time focus of human life?

d. Activity Orientation: What is the method of human activity?

e. Human Relationships Orientation: What is the way a person relates to his other peers?

(Hall \& Hall, 1990) While the anthropologist presented (Hall) four valuable dimensions to help managers understand the behavior of workers, based on his experience, which he conducted in 180 open interviews with people working in the field of business, and the results were as follows as follows:

a. Fast and slow messaging: Determining the speed with which a particular message can be decoded and dealt with is one of the most important characteristics of human communication.

b. High and low context: The amount of sufficient information surrounding the event; It is closely related to the meaning of the event, and that the elements that combine to produce meaningful events and a deceptive text of the nature of the event are in different proportions depending on the culture; With which the cultures of the world can be compared on a large scale.

c. Space: Every living being has a visible physical boundary that separates it from its external environment. This visible boundary is surrounded by a series of invisible boundaries that are difficult to define, but are real and exist, starting with the individual's personal space and ending with his "land or area".

d. Time: Life on Earth has evolved in response to the evolution of humanity, and the multiplicity of biological clocks that regulate most of the physiological functions of our bodies, so it is not surprising that human concepts of time have emerged from the natural rhythms associated with daily, monthly and annual cycles, and from this background two systems arose Two temporal ones are "time as a structure" and "time as a continuum".

As for the study (Hofstede, 1980), which began (1968-1972), it included the following dimensions (Hofstede, 2011):

a. Power distance - PD: Define power inequality as the extent to which less powerful members of organizations and institutions accept and expect power to be distributed unequally. It indicates that the level of inequality in society is supported by followers. As far as leaders endorse it, power and inequality are key facts of inequality in any society.

b. Uncertainty Avoidance - UA: This dimension refers to the community's feeling of satisfaction or discomfort in unknown and surprising situations or different from the usual dealing, which can be reduced through strict laws and behavioral rules, rejection of deviant opinions, and belief in the truth.

c. Individualism versus collectivism (Individualism VC Collectivism - IVC): It is the degree of integration within society into groups, as there are cultures in which individual ties dominate 
the relationships between their members, on the contrary, there are cultures in which people merge from birth into strong and cohesive groups and their loyalty is Indisputable.

d. Masculinity VS Femininity - MVF: IBM studies revealed that women's values differ to a lesser degree than men in societies, while men's values differ in terms of firmness and competitiveness versus modesty and care for women's values from one society to another.

e. Long-Term vs. Short-Term Orientation - LTO: This dimension was identified for the first time in a survey of students from (23) countries, in a study of their beginnings (Bond), it was found that this dimension is strongly linked to economic growth, Its values included perseverance, thrift, and relationships based on social status, in exchange for reciprocal social obligations, respect for tradition, protection of reputation, and personal fortitude and stability.

f. Indulgence VC Restraint - IVR: This dimension was added in (2010) based on a study conducted by (Minkov's, 2000) that included (93) countries; It focuses on aspects not covered by the other five dimensions, as indulgence represents the free satisfaction of basic and natural human desires related to the enjoyment of life and pleasure, while self-control represents a society that controls and regulates the satisfaction of needs through strict social standards.

\subsection{The Impact of Cultural Dimensions in Decision Making}

(Vitell, 1993)Several studies have emerged that have been concerned with studying the impact of cultural dimensions, perhaps the most prominent of which is the study (Barrels, 1967), which dealt with social and ethical responsibility in business and the role of cultural dimensions; In making decisions and taking into account the legal aspects, personality, national identity, and property rights, based on (moral theory) that focuses on specific actions or behaviors of the individual, or (purpose theory) which is concerned with the consequences of those actions or behaviors

(Podrug, 2006) In general, business communities cannot distance themselves from the effects of cultural dimensions, as they aim to protect their interests, and as an inevitable result of the globalization of the economy, the importance of cultural influence on management and its behavior within the economic unit has increased, as it is a reflection of its environment in which it deals, and its techniques applied in decision-making as follows:

a. 1 Autocratic Use of directly available information without advice.

b. 2 Consultative There is prior consultation with others whose opinions may be reflected in the decision taken.

c. 3 Pseudo - Consultative Consultation with others without taking into account their opinions and suggestions.

d. 4 Participation in the decision Evaluation of alternatives, decision-making by majority.

e. 5 Pseudo - Participative Evaluate alternatives, and decide in advance.

f. 6 Delegatory Authorizing the power to make decisions.

(Rogerson et al, 2011) However, decision-making can be complex when decisions include complex and conflicting situations, vague or non-existent guidelines, and as a result, decision-making is based on a number of influencing factors and available options, which can lead to many pathways that can Controlling it by dividing the decision-making process and studying the impact of the cultural and ethical dimension, given that management is nothing but an agent for others in the decision-making process, which aims to preserve capital and achieve the wishes of its clients, which was confirmed by the normative theory when making a decision.

(Ford and Kotzé, 2005) indicate that culture affects the way in which the business environment interacts, as well as the way in which society communicates with the system and the user, and accordingly, people learn patterns of thinking, behaving and communicating by living in a social environment defined by cultural patterns, which usually What distinguishes it from national culture, and accordingly, culture predetermines the preferences and behaviors of communication between 
cultural patterns and values, through a number of environmental influences, foremost of which is technological development, which has contributed to changing the pattern of doing business and the interaction between society and institutions.

(Ho et al, 2012) believes that the cultural impact on the performance of economic units has become a reality in the past few decades, due to the realization that business organizations are not only an economic entity with a legal personality, but also have social responsibilities towards various stakeholders and the surrounding environment, as well as The existence of new variables and connections, due to the globalization of the economy and the expansion of trade, stakeholders began to assert or expect more social responsibilities from economic units, including the surrounding cultural environment and their social and environmental obligations.

Also (Abdullahi \& Zainol, 2016) believes that the socially built reality when workers create a social framework, turns into an effective reality that forms a behavioral pattern that affects the business environment, and as a result, all intangible things, which directly or indirectly affect decisionmaking, are called It (the social and cultural business environment), which refers to a set of common core values that contribute to shaping the behavior of individuals working in the business environment.

The researcher believes that there are rarely homogeneous societies with a unified culture, which has been proven in many studies, that cultures affect societal behaviors, and as a result society's interaction with the business environment, and the resulting economic consequences related to satisfaction or non-acceptance, which was indicated It is concerned with how to make a decision depending on the level of participation, and the evaluation of available alternatives, so the reaction is related to how to respond to the emerging variables, whether related to adaptation or mitigating the risks associated with decision-making, and cultural dimensions can be viewed as an integral part of the prevailing patterns of production and consumption. life and social organization.

As a result, we must understand how people's mindset, perception or behavior affect the success or failure of the business environment in achieving its goals, and how it can help the economic unit to manage its resources, more effectively, and reduce potential undesirable cultural biases that can affect The decision-making path, as the organizational culture of the administration, can affect the level of performance improvement and the effectiveness of communication at the organizational and personal level with the workers in the economic unit or the beneficiaries of its outputs, whether services or data intended to be used for decision-making.

\subsection{The Concept of Information Quality in Integrated Reporting}

(Cortesi \& Vena, 2019) defines it as the increased demand for information provided by economic units in their reports, whether voluntary or mandatory. It has led to an increase in the amount of information it discloses clearly over the past decades. This prompted the issuance of various reports such as financial reports, corporate governance, and social responsibility, to meet the growing need for beneficiaries.

While (Miron et al, 2004) sees that the presence of fragmented and confusing reports, and raising dissatisfaction with the economic unit reports models, led to gaps in the nature of information that may hinder decision-making, which can be avoided by issuing consolidated and consolidated reports that enhance the transparency and quality of information, As a result, the focus on quality has increased.

With the beginning of the emergence of quality measurement standards (ISO) and the adoption of the main requirements for them, and obligating organizations to develop and implement a set of procedures, to ensure that the beneficiary obtains the maximum quality from the economic unit.

Or as (Elshaer, 2012) defines it as the situation in which a set of inherent characteristics meets the ever-changing requirements of beneficiaries and other stakeholders, and in general quality can be defined as an essential tool for comparing specifications. 
(Diaz, 2014) refers to the set of characteristics inherent in an element, and also allows meeting the stated or implicit needs of the beneficiaries, and as a result, the quality is the beneficiary's perception of it, or it is a mentality that accepts the specifications and its ability to meet his needs.

(Cooray et al, 2020)Over the past few decades, stakeholders' demand for environmental, social, financial and administrative information has increased significantly, which has encouraged the creation of a new form of reporting in light of the emergence of international relations, as a new dimension to the reports issued by economic units, in an attempt to make them more effective to improve The efficiency of administrative and investment decision-making, with regard to improving the quality of information available to capital providers, which is achieved by integrated reports, in sharing environmental, social, financial, non-financial and governance information in one report, based on concepts and principles aimed at providing a more efficient and coherent reporting system.

(Songini et al, 2021) As a result, the board of directors plays a very important role, as it represents the role of the defender of its higher interests in achieving the quality of disclosure, and in line with the representation of the interests of other beneficiaries, within an integrated thinking environment, as a determining factor for the voluntary disclosure mechanisms of the economic unit, which may affect the quality of the information provided. Since the board of directors is the main decision-maker, responsible for managing and protecting the available resources, and making the most possible use of the wishes of the various stakeholders.

(John1988, Pavlopoulos et al 2019) Since integrated reports are the latest form of reporting reports that depend on the information provided by the administration, this makes it difficult to verify them as a result of several factors that can be summarized as follows:

a. The intangible nature of information quality means that it is difficult to describe and define what the user wants from it.

b. The heterogeneity of information is difficult to assess, and its relative importance can change rapidly.

c. The participation of information beneficiaries in creating and achieving quality information requires continuous modification of the methods of its presentation and disclosure.

Accordingly, the quality of the information provided by the integrated reports, which makes them more important, comes from its impact on creating future value, which was not previously considered in the preparation of financial reports.

\subsection{Integrated reporting quality}

(IIRC, 2013) indicates that Integrated Report Quality conceptually refers to the degree of compliance of integrated reports and their submission to the practice of governance, from those responsible for preparing integrated reports, as well as the environment for the organization to determine the material matters, and how to disclose them in the integrated reports. As a result, the management of the unit The Economist has discretion in what it chooses to disclose, which will lead to different levels of alignment between the integrated reporting and the conceptual framework.

(Moloi, 2020), which seeks to produce integrated, high-quality, long-term reports as part of the prevailing business practices in the public and private sectors, with the aim of improving the quality of available information.

Disclosure of financial and non-financial information is of value to stakeholders and capital providers in particular, and to provide them with both forms of information in one comprehensive report, to create and enhance long-term value, and to disclose financial and non-financial information in a complementary way, enabling them to evaluate the available opportunities in a way More effective, more intensive control of capital investment, and this is the goal that integrated reports strive to achieve. 
The conceptual framework of integrated reports (IIRC) is also integrated with the general framework for management ethics issued by the Institute of Management Accountants (IMA), regarding the need to achieve a high level of quality of the information disclosed, and that the administration adhere to a number of standards that lead to enhancing efficiency and confidentiality , integrity, and credibility, which includes the following (IMA, 2017):

a. Competence: means maintaining an appropriate level of professional leadership and experience, by enhancing knowledge and skills, to carry out professional duties in accordance with relevant laws, regulations and technical standards, to provide accurate, clear, concise and timely information that contributes to risk detection and assistance in its management.

b. Confidentiality: Maintaining the confidentiality of information must be in accordance with the laws and regulations that allow this, as a result of maintaining market competitiveness, and to be declared as part of compliance with governance requirements.

c. Integrity: It means the necessity of achieving the principle of non-conflict of interest, and not refraining from using confidential information for unethical or illegal advantages, or any behavior that would lead to material or moral harm to others.

d. Credibility: Delivering information fairly and objectively is one of the most important priorities of the administration that can be expected from stakeholders, including reporting restrictions that would affect the decision taken as a result of the lack of clarity of information.

(Remenaric et al, 2019) that the reports provided by the economic unit represent the link with other parties. Through the information provided in the various reports, stakeholders make their decisions based on this information, and in order to be able to make decisions, they must That the information contained therein be accurate and reliable, however, most economic units at the present time, increasingly resort to smoothing the financial statements, in order to present a more attractive picture to the largest possible number of investors.

Also, providing information in a transparent manner to stakeholders helps them make informed decisions, so any event that is likely to affect the current financial position of the economic unit, or future risks, must be indicated in those reports.

\subsection{Factors affecting the quality of integrated reports}

(Owen, 2013, Guthrie et al 2020, Vitolla et al, 2019) There is a historical fact that proves that the preparation of reports evolves directly with the changing information needs of decision makers, and to realize the shortcomings in meeting the needs for data and information, economic units adapt themselves to modernize their reporting system, as well as the effects of the surrounding environment have a role in determining how to disclose Information, country-specific factors, influence reporting preferences using the perspective of institutional theory, which states that organizations are embedded in a comprehensive system of political, financial, educational, cultural, and economic institutions that pressure departments to disclose information. The adequacy of reports in meeting the information needs of beneficiaries is questionable to disclose risks, reduce uncertainty, improve regulatory transparency, and stakeholders' decision-making processes, and financial reports overlook types of risks that pose a threat to organizational sustainability and society. As a result, integrated reports have emerged, as a more comprehensive and updated reporting system, aimed at meeting the needs of all stakeholders, instead of preparing stand-alone reports with a targeted goal, such as sustainability reports, financial reports, and other reports produced by management to disclose specific information with a context focused on A specific goal, which means that economic units adopt integrated reports, not just to reform the quality of disclosure in them. In order to understand the current reporting process, the factors affecting the quality of integrated reports must be studied, which include the following (Jensen, J. C., \& Berg, 2012): 
a. Political System: The importance of the political system is classified by distinguishing between the economic and social dimensions of legal protection, these dimensions are the level of investor protection and the level of protection of the economic unit, which makes investment protection the main point of disclosure, because the main objective of reporting in work environments With high shareholder protection, is to meet shareholder needs for financial information, it is expected that there will be less tendency towards integrated reporting.

b. Legal System: Given that companies are subject to special rules and regulations and the extent to which they adopt the main characteristics of the applicable legal system, the public law system focuses on protecting investors and shareholders, while the private system, from a societal perspective, tends to protect the rights of workers and other stakeholders, That is, the quality of disclosure and reporting in the reports is subject to a number of legal variables, which are imposed by the environment in which the economic unit operates.

c. The Financial System: The financial system is the most important determinant of data dissemination in integrated reports, depending on the economy of the country in which the economic unit operates, as it analyzes the financial system in general using the degree of market orientation as a basis, whether it is a bank-based or dependent economy On the market in the first place, in bank-based economies such as Japan and Germany, there are direct relationships between banks and economic units, to obtain information, data and access to information systems, as banks can monitor the behavior of economic units intensively, and as a result, the demand for integrated reports will decrease In market-based economies, reports are prepared for the purpose of building investment decisions from stakeholders, based on the differentiation of data presented in integrated reports.

d. Education \& Labor Systems: The level of investment made by the state in education is an important factor in the reporting process. Economic units operating in countries with higher education show a strong interest in research results and academic knowledge, and adopt reporting techniques at a time. Earlier, than those in countries with low interest in higher education, as well as for labor systems, trade unions that collectively represent the interests of workers, and which reflect an indicator of social and political progress, are often involved, since integrated reports will reflect the values of economic, cultural and social unity.

e. Cultural System: Cultural dimensions explain the general similarities and differences in cultures around the world, and there are specific relationships between these dimensions and the preferences and actions of stakeholders, and that different cultural dimensions - gender equality, institutional collectivism, or human orientation - reflect Significant differences in accounting practices, or in the publication of different types of reports, in some countries the focus is on financial well-being, while in others the responsibility of economic units includes a broader set of environmental and social values, which support values of self-expression, and also give high priority To protect the environment, the value of broad participation in decision-making in economic and political life, as well as group thinking increases the likelihood of integrated reporting compared to individualism, because group thinking requires a higher level of commitment to society, and to act as a member of the group, rather than the individual economic unit.

f. Economic System: The level of development of the economic system is a determining factor in the preferences of the economic unit of the integrated reporting system, and this increases the possibility of innovations emerging in developed countries, as they have a higher probability of applying new management tools for disclosure, earlier than those Existing in least developed countries, it is recognized in the literature that the level of economic development has a positive impact on integrated reporting. 


\section{Mythology}

The methodology represents a map for arranging the researcher's ideas to present the research problem, its importance and the goals that the researcher seeks to achieve, based on scientifically formulated research or mental hypotheses, and linking them with the diagnosed problems to know the level of availability of solutions and theoretical accessibility by analyzing data or opinions that can be collected from the research sample and as a result The proposed research methodology.

The process of reporting the results of the business of the economic unit is tainted by various problems that prompted the emergence of an advanced type of reports, which aims to achieve a higher level of quality of accounting reporting, and on the other hand shows a set of dimensions that affect the behavioral aspects, to know the effects associated with the work of economic units, whether they are Those influences are social, environmental, or internal, related to how management deals with them and make decisions, which appeared in the form of integrated reporting, and the impact of cultural dimensions on the quality of integrated reports.

And research importance from Quality problems in reporting business results are one of the matters of importance to the beneficiaries of financial reports, and as a result of the expansion of business and the economic and financial overlap of various economic activities and sectors, financial information has become insufficient to take effective decisions with a future dimension, as a result of which the need for more detailed reports has emerged. It is presented to stakeholders to know the effects associated with the work of economic units, whether those effects are social, environmental or internal, related to how the administration deals with it and take internal decisions, which appeared in the form of integrated reporting and the extent of the impact of cultural dimensions on the quality of integrated reporting.

The research seeks to identify the cultural dimensions and their impact on the quality of integrated reports, and shed light on the role of cultural dimensions in the decisions of the Board of Directors and the selection of disclosure mechanisms in the integrated reports.

The research is based on a main hypothesis that states "there is a significant statistically significant relationship at the level (0.005) between the cultural dimensions of (Hofstede) and the quality of reporting in the integrated reports."

\section{Data collection and analysis}

For the purpose of measuring the impact of cultural dimensions on the quality of integrated reports from the point of view of management, stakeholders and other beneficiaries, a questionnaire was designed that includes the main cultural dimensions mentioned by (Hofstede 2010) as follows:

a. Power Distance PD

b. Individualism VC Collectivism UA

c. Uncertainty Avoidance IVC

d. Masculinity VS Femininity MVF

e. Long-Term vs. Short-Term Orientation LTO

f. Indulgence VC Restraint IVR

The questionnaire included (6) main axes, each of which contains (10) paragraphs, which can affect the behavior of the preparers of integrated reports, and the quality of the information contained therein. Simplicity and clarity were taken into account in its formulation as a tool for collecting the necessary data and information.

For the purpose of measuring the stability of the internal consistency between the paragraphs of the axis, the stability index (Cronbach's Alpha) was used, which is a measure coefficient of the reliability of the test and the most common and appropriate for scales with graduated weights, as follows: 
www.techniumscience.com

\begin{tabular}{|c|c|c|}
\hline \multicolumn{3}{|c|}{ Table (1)Reliability Statistics } \\
\hline Cronbach's Alpha & $\begin{array}{c}\text { Cronbach's Alpha Based on } \\
\text { Standardized Items }\end{array}$ & N of Items \\
\hline .900 & .911 & 7 \\
\hline
\end{tabular}

And whose validity can be enhanced by conducting a parametric test (Pearson Correlation coefficient), to measure the value of the change in the dependent variable, the quality of integrated reports, which is symbolized by the symbol $(\mathrm{Y})$ as a result of the change in the value of the independent variable, which is the cultural dimensions of (Hofstede), which is symbolized by the symbol (X), which is shown in Table (2).

\begin{tabular}{|c|c|c|c|c|c|c|c|}
\hline \multicolumn{8}{|c|}{ Table (2) Inter-Item Correlation Matrix } \\
\hline & PD & UA & IVC & MVF & LTO & IVR & $\begin{array}{c}\text { Culture } \\
\text { dimension }\end{array}$ \\
\hline PD & $\mathbf{1 . 0 0 0}$ & .681 & .624 & .355 & .649 & .648 & .839 \\
\hline UA & .681 & 1.000 & .655 & .114 & .669 & .719 & .817 \\
\hline IVC & .624 & .655 & 1.000 & .301 & .654 & .634 & .828 \\
\hline MVF & .355 & .114 & .301 & 1.000 & .191 & .248 & .490 \\
\hline LTO & .649 & .669 & .654 & .191 & 1.000 & .698 & .833 \\
\hline IVR & .648 & .719 & .634 & .248 & .698 & 1.000 & .848 \\
\hline $\begin{array}{c}\text { Culture } \\
\text { dimension }\end{array}$ & .839 & .817 & .828 & .490 & .833 & .848 & 1.000 \\
\hline
\end{tabular}

In addition to the above, the business environment in which administrative and investment decisions are made, has an impact on the nature of the behaviors and trends that the decision maker can adopt, and for the purpose of knowing the impact of the subjective characteristics of the research sample and ensuring the link between them and the trends of cultural dimensions, within the axes of the questionnaire, which came as In Table (3) as follows:

\begin{tabular}{|c|c|c|c|c|c|c|}
\hline \multicolumn{7}{|c|}{ Table (3) ANOVA ${ }^{\mathrm{a}}$} \\
\hline \multicolumn{2}{|c|}{ Model } & $\begin{array}{c}\text { Sum of } \\
\text { Squares }\end{array}$ & df & Mean Square & $\mathbf{F}$ & Sig. \\
\hline \multirow{3}{*}{1} & Regression & 3.617 & 5 & .723 & 6.389 & $.000^{b}$ \\
\hline & Residual & 20.155 & 178 & .113 & & \\
\hline & Total & 23.771 & 183 & & & \\
\hline \multicolumn{7}{|c|}{ الثقافية الابعاد الج a. Dependent Variable } \\
\hline \multicolumn{7}{|c|}{$\begin{array}{l}\text { a. Dependent Variable: culture dimension } \\
\text { b. Predictors: (Constant): gender, work experience, type of work, workplace, educational } \\
\text { attainment }\end{array}$} \\
\hline
\end{tabular}

The quality of integrated reports depends on the quality of the information contained in the financial and non-financial statements (management report), depending on the relationships provided by those reports between its paragraphs, which can provide an advanced vision in integrated reporting, and reflect how the economic unit creates current and future value. For the purpose of measuring the quality of integrated reports, many previous studies and research have been reviewed, for the purpose of forming a more realistic picture that can be applied in the Iraqi environment, based on what is disclosed in its annual reports. et al, 2018, which focused on four main elements of the content of the integrated reports, which included the background that the economic unit enjoys in presenting its reports, the extent to which the credibility of the disclosed data is ensured, and the absence of conflict of interest with the beneficiaries by enhancing the reliability of integrated reporting, clarity of content and Data presentation independence.

As for the study (Raimo et al, 2019), it focused on the extent to which economic units comply with the conceptual framework issued by the International Integrated Reporting Council (IRCC), which included the strategy of the economic unit, resource allocation, governance, the relationship with the external environment, future risks and opportunities, and their relationship The cultural dimensions, 
which depended on measuring their values within the national cultural environment of the research sample.

While the study (Moli, 2020) relied on the classification of the (Ernst \& Young) institution in measuring the quality of integrated reports, based on a comparison between the degree of disclosure and its relationship with the governance of the economic unit, which focuses on the distribution of powers between decision-making centers.

As a result, the model for measuring the quality of the integrated reports presented by the study, to measure the quality of the integrated reports, issued by the research sample units and which the researcher assumes within the research sample, according to the following:

IR QUALITY $=\beta 0+\beta 1$ PER + $\beta 2$ SIZE + $\beta 3$ ROE + $\beta 4$ SHARE P. + $\beta 5$ PD + $\beta 6$ UA + $\beta 7$ IVC + $\beta 8$ $\mathrm{MVF}+\beta 9 \mathrm{LTO}+\beta 10 \mathrm{IVR}+\beta 11 \mathrm{SEN}+\varepsilon$.

It represents the following elements:

-(PER) reflects the performance of the economic unit in the financial markets in the long and short term, as well as helps in complying with the standards, instructions and laws related to publishing and amending financial and non-financial reports.

-(SIZE) The size of the economic unit, which is the ratio of the assets of the sectoral economic unit.

-(ROE) Return on Equity, which was chosen because the economic performance is the factor that determines the quality of its reports, bearing in mind that preparing an integrated report has high costs.

-(SHARE P.) The share price in the financial markets, as it reflects the confidence of investors in the performance of the economic unit.

-(PD) Power inequality which is the extent to which power is used and strategic decisions are made.

-(UA) Uncertainty avoidance is the ability of an economic unit to predict future events.

-(IVC) individual versus collective, which represents the ability of an economic unit to distribute powers and make decisions collectively or individually.

-(MVF) Masculinity versus femininity, which represents the competitiveness and diversity in forming opinions and occupying positions and the reliability of decisions made by the opposite sex.

-(LTO) Long-term versus short-term orientation, which means future-oriented economic unit behaviors such as planning and investment.

-(IVR) Tolerance versus restraint, which is the extent to which societal adherence to strict standards.

-(SEN) represents the environmental sensitivity of the industry in which the economic unit operates. This variable has a value of (1) if the activities of the economic unit have an impact on the environment.

Table (4) shows the measurement of the quality of integrated reports according to equation (1) for the research sample, which consisted of 20 companies listed on the Iraq Stock Exchange.

\begin{tabular}{|l|r|r|r|r|r|}
\hline \multicolumn{7}{|c|}{ Table (4) Descriptive Statistics } \\
\hline & N & Minimum & Maximum & Mean & Std. Deviation \\
\hline IRQ2018 & $\mathbf{2 0}$ & $\mathbf{2 7 . 6 9}$ & $\mathbf{5 0 . 8 9}$ & $\mathbf{3 9 . 3 7 0 4}$ & $\mathbf{6 . 0 0 8 6 2}$ \\
\hline IRQ2019 & $\mathbf{2 0}$ & $\mathbf{2 8 . 7 9}$ & $\mathbf{5 4 . 9 0}$ & $\mathbf{4 0 . 5 4 7 7}$ & $\mathbf{6 . 3 7 2 0 0}$ \\
\hline IRQ2020 & $\mathbf{2 0}$ & $\mathbf{2 9 . 5 7}$ & $\mathbf{5 2 . 6 3}$ & $\mathbf{4 1 . 4 2 0 1}$ & $\mathbf{5 . 7 2 2 0 0}$ \\
\hline Valid N (Listwise) & $\mathbf{2 0}$ & & & & \\
\hline
\end{tabular}

For the purpose of linking the variables of equation (1), and knowing the relationship of the dependent variable $(Y)$, which represents the quality of integrated reports, to the independent variable $(\mathrm{X})$, which represents the variables assumed in equation (1) and their impact on the quality of integrated reports, which can be clarified in Table (5) as follows: 


\section{Technium Sustainability}

www.techniumscience.com

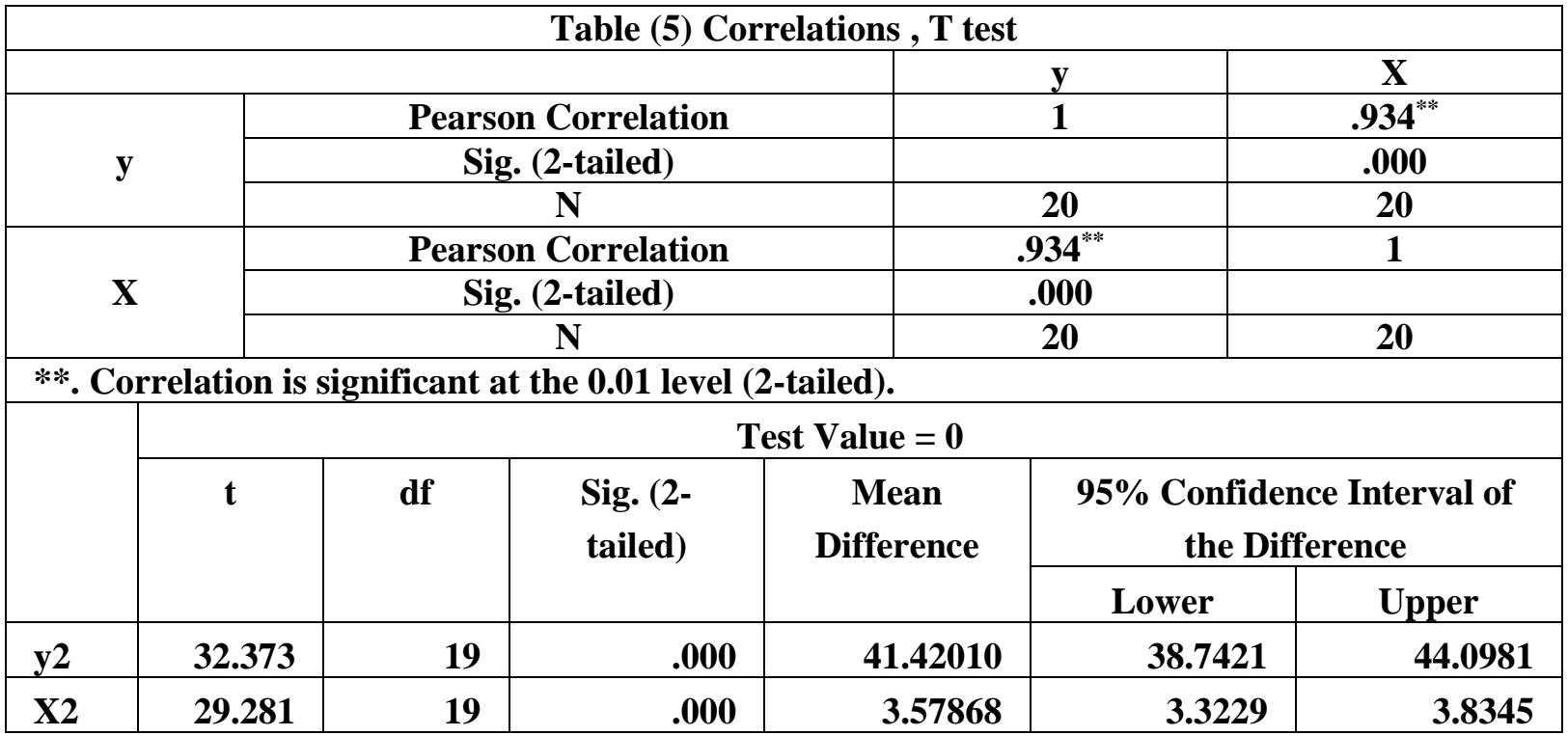

As for the degree of influence of the independent variables in equation (1) on the dependent variable, which represents the quality of the integrated reporting, it can be measured by the linear regression equation, which states:

$$
Y=a+\beta 1 X 1
$$

Where (a) Constant represents the amount of the constant and this relationship means that the quality of the integrated reporting $(\mathrm{Y})$ is a function of the true value of the effect of the independent variables $(\mathrm{X})$ in equation (1) shown in the following table (6):

\begin{tabular}{|c|c|c|c|c|c|c|}
\hline \multicolumn{7}{|c|}{ Table (6) ANOVA ${ }^{\mathrm{a}}$} \\
\hline \multicolumn{2}{|c|}{ Model } & $\begin{array}{l}\text { Sum of } \\
\text { Squares }\end{array}$ & df & Mean Square & $\mathbf{F}$ & Sig. \\
\hline \multirow[t]{3}{*}{1} & Regression & 4.951 & 1 & 4.951 & 12.879 & $.000^{b}$ \\
\hline & Residual & .725 & 18 & .040 & & \\
\hline & Total & 5.676 & 19 & & & \\
\hline \multicolumn{7}{|c|}{ a. Dependent Variable: $X$} \\
\hline \multicolumn{7}{|c|}{ b. Predictors: (Constant), y } \\
\hline
\end{tabular}

\section{Discussion}

The change in the business environment and its economic complexities, created a kind of deficiency in financial reports in meeting the needs of the renewed information needs of stakeholders, and the inability to keep pace with developments, due to its focus on financial information only that pertains to operational and investment activities.

As a result, the integrated reporting process is the result of the development of the need for integrated information, which aims to unify the reports issued by economic units of all kinds, financial and non-financial, and sustainability reports in a unified manner, facilitating the process of reading them from the main stakeholders and other beneficiaries, and which requires the departments, to adhere to the conceptual framework of integrated reports. (IR), in addition to the International Accounting Standards (IAS) and Financial Reporting Standards (IFRS), and the extent to which they apply the concept of integrated strategic thinking.

Since the economic unit is part of a social environment, representing its business environment, it affects and is affected by the values of that society or what is known as cultural dimensions, which can be of a sensitive nature, in integrated reporting practices and as a result its reflection on the value of 
the economic unit, as the results show that the dimensions Cultural plays an important role, in the integrated reporting of economic units, because of the nature of the formation of the social personality of those responsible for their numbers, in addition to the above, the business environment, in which administrative and investment decisions are made, has an impact on the nature of the behaviors and directions that the decision maker can adopt.

Culture is a factor affecting human behavior in particular and society in general, and its values in general, and cannot be neglected or dispensed with, in the formation of personal or social and economic practices, and as a result, its impact on accounting practices cannot be neglected as it is part of society, it affects and is affected by cultural behaviors that reflect Personal characteristics of stakeholders. Societies are usually classified according to cultural concepts that reflect the level of awareness, development, and adherence to societal customs and values.

\section{Recommendations}

Understanding how the human mindset or behavior affects the success or failure of the business environment in achieving its goals is important to help the economic unit manage its resources more effectively, and reduce potential undesirable cultural biases, which can affect the course of decisionmaking, as The organizational culture of the administration can affect the level of performance improvement and the effectiveness of communication at the organizational and personal level with the workers in the economic unit or the beneficiaries of its outputs, whether services or data intended to be used for decision-making.

The significance of the integrated reporting quality enables the stakeholders and beneficiaries of the reports published by the economic unit to know the accuracy of the economic unit's disclosure of its financial and non-financial activities, and that the difference in the quality of the integrated reports of the economic units, the research sample, and their variation in some cases is due to the different methods of preparing financial and non-financial reports. financial as well as fluctuations in economic activity within the business environment.

\section{Prospects and future studies}

There is no doubt that the adoption of integrated reports is an advanced stage in reporting the financial and non-financial activities of the economic unit, but it is only a station in the process of continuous development, as the International Integrated Reporting Council (IIRC) and the Sustainability Accounting Standards Board (SASB), officially announced their merger to form a reporting institution. The Value Reporting Foundation, to support business and investor decisionmaking with three key resources, including Integrated Thinking Principles, Integrated Reporting Framework, and Sustainability Accounting Standards, to help business units and stakeholders develop a shared understanding of business unit value, and how it is created, maintained, or eroded. Over time, VRF is also committed to providing a more coherent reporting system by working with the International Financial Reporting Standards Board (ISAB).

\section{Reference}

[1] Abdullahi, A. I., \& Zainol, F. A. (2016). The impact of socio-cultural business environment on entrepreneurial intention: A conceptual approach. International Journal of Academic Research in Business and Social Sciences, 6(2), 80-94.

[2] Cooray, T., Gunarathne, A,D., \& Senaratne, S, (2020), Does Corporate Governance Affect the Quality of Integrated Reporting?, Sustainability, 12(10),pp. 4262-4292.

[3] Cortesi, A., \& Vena, L. (2019). Disclosure quality under integrated reporting: a value relevance approach. Journal of cleaner production,pp.745-755.

[4] Diaz, (2014), What is your definition of quality?, Geneva Business, 1-4, https://www, gbnews,com. 
[5] Elshaer, Ibrahim,. (2012), What is the Meaning of Quality?, Munich Personal RePEc Archive, https://mpra.ub.uni-Muenchen.

[6] Fink, G, Neyer, A, K, \& Kölling, M, (2006), Understanding cross-cultural management interaction: Research into cultural standards to complement cultural value dimensions and personality traits, International Studies of Management \& Organization, 36(4), 38-60.

[7] Ford, G, \& Kotzé, P, (2005, September), Designing usable interfaces with cultural dimensions, In IFIP Conference on Human-Computer Interaction, Springer, Berlin, Heidelberg, (pp, 713-726).

[8] Guthrie, J., Rossi, F. M., Orelli, R. L., \& Nicolò, G. (2020). Investigating risk disclosures in Italian integrated reports. Meditari Accountancy Research., pp.1-30.

[9] Hall, E,T, and M,R, Hall, 1990, Understanding Cultural Differences: Keys to Success in West Germany, France and the United States, Yarmouth, ME: Intercultural Press.

[10] Ho, F. N., Wang, H. M. D., \& Vitell, S. J. (2012). A global analysis of corporate social performance: The effects of cultural and geographic environments. Journal of business ethics, 107(4), 423-433.

[11] Hofstede, G, (2011), Dimensional zing Cultures: The Hofstede Model in Context, Online Readings in Psychology and Culture, Unit 2, Retrieved from http://scholarworks, gvsu,edu/orpc/vol2/iss 1/8.

[12] IIRC, (2013), THE International 〈IR> Framework, The International Integrated Reporting Council, UK, pp.1-35.

[13] IMA, (2017) Statement of Ethical Professional Practice, Institute of Management Accountants, USA.

[14] Jensen, J. C., \& Berg, N. (2012). Determinants of traditional sustainability reporting versus integrated reporting. An institutionalist approach. Business Strategy and the Environment, 21(5), 299-316.

[15] Miron, E., Erez, M., \& Naveh, E, (2004), Do personal characteristics and cultural values that promote innovation, quality, and efficiency compete or complement each other?, Journal of organizational behavior, 25(2), 175-199.

[16] Moloi, T, \& Iredele, O, (2020), Firm Value and Integrated Reporting Quality of South African Listed Firms, Academy of Strategic Management Journal, 19(1), 1-12.

[17] Owen, G. (2013). Integrated reporting: A review of developments and their implications for the accounting curriculum. Accounting Education, 22(4), 340-356.

[18] Pavlopoulos, A., Magnis, C., \& Iatridis, G. E. (2019). Integrated reporting: An accounting disclosure tool for high quality financial reporting. Research in International Business and Finance, 49, 13-40.

[19] Podrug, N,, Pavičić, J,, \& Bratić, V, (2006), Cross-cultural comparison of Hofstede's dimensions and decision-making style within CEE context, In From transition to sustainable development: The path to European integration, 1-16.

[20] Raimo, Nicola; Zito, Marianna; Caragnano, Alessandra (2019), "Does national culture affect integrated reporting quality? A focus on GLOBE dimensions", Mihajlović, Dragan Đorđević, Bojan (Ed,): 9th International Symposium on Natural Resources Management, May 31st, 2019, Zaječar, Serbia, ISBN 978-86-7747-606-9, pp, 383392.

[21] Remenarić, B., Kenfelja, I., \& Mijoč, I. (2018). Creative accounting-motives, techniques and possibilities of prevention. Ekonomski vjesnik, 31(1), 193-199.

[22] Rogerson, M. D., Gottlieb, M. C., Handelsman, M. M., Knapp, S., \& Younggren, J. (2011). Nonrational processes in ethical decision making. American Psychologist, 66(7), 614. 


\section{Technium Sustainability}

[23] Songini, L., Pistoni, A., Tettamanzi, P., Fratini, F., \& Minutiello, V. (2021). Integrated reporting quality and $\mathrm{BoD}$ characteristics: an empirical analysis. Journal of Management and Governance, 1-42.

[24] Vitell, S, J,, Nwachukwu, S, L, \& Barnes, J, H, (1993), The effects of culture on ethical decision-making: An application of Hofstede's typology, Journal of business Ethics, 12(10), 753-760.

[25] Vitolla, F., Raimo, N., Marrone, A., \& Rubino, M. (2019). The role of board of directors in intellectual capital disclosure after the advent of integrated reporting. Corporate Social Responsibility and Environmental Management,pp.1-16. 